\title{
“Trend analysis of aerosol optical thickness and Ångström exponent derived from the global AERONET spectral observations" published in Atmos. Meas. Tech., 5, 1271-1299, 2012
}

J. Yoon, W. von Hoyningen-Huene, A. A. Kokhanovsky, M. Vountas, and J. P. Burrows Institute of Environmental Physics, University of Bremen, Bremen, Germany

Correspondence to: J. Yoon (yoon@iup.physik.uni-bremen.de)

We would like to inform you that the footnote of Table 2 contains a mistake. Here you will find the right equation for *-footnote of Table 2:

$$
\begin{aligned}
\frac{\mathrm{d} V(r)}{\mathrm{d} \ln r} & =\frac{C_{\text {fine }}}{\sqrt{2 \pi} \sigma_{\text {fine }}} \exp \left[-\frac{\left(\ln r-\ln r_{\text {fine }}\right)^{2}}{2 \sigma_{\text {fine }}^{2}}\right] \\
& +\frac{C_{\text {coarse }}}{\sqrt{2 \pi} \sigma_{\text {coarse }}} \exp \left[-\frac{\left(\ln r-\ln r_{\text {coarse }}\right)^{2}}{2 \sigma_{\text {coarse }}^{2}}\right]
\end{aligned}
$$

